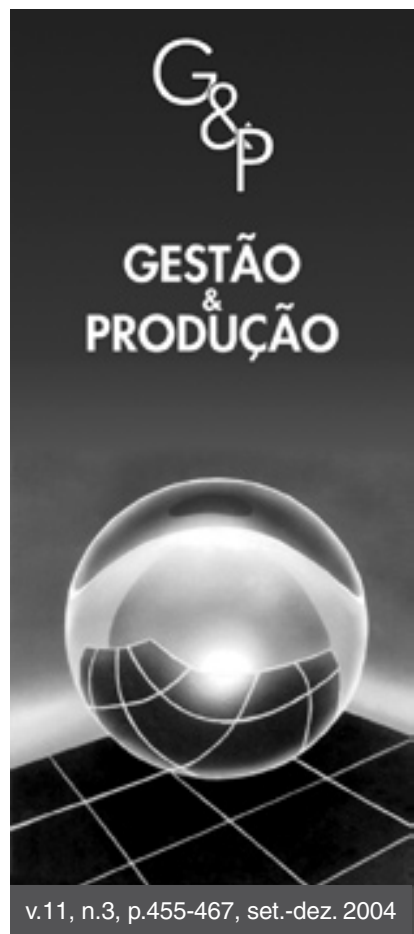

\title{
IMPACTOS DA SOFISTICAÇÃO LOGÍSTICA DE EMPRESAS INDUSTRIAIS NAS MOTIVAÇÕES PARA TERCEIRIZAÇÃO
}

\author{
Peter Wanke \\ Centro de Estudos em Logística, Instituto COPPEAD de Administração,UFRJ, \\ Ed. COPPEAD, Cid. Universitária, Ilha do Fundão , \\ CEP 21949-900, Rio de Janeiro - RJ, \\ e-mail: peter@ coppead.ufrj.br
}

Resumo

O objetivo desta pesquisa é avaliar o impacto das diferentes dimensões de sofisticação da organização logística das empresas brasileiras do setor industrial, nas motivações para a terceirização de atividades logísticas. Para isto, foram definidas e operacionalizadas, com base em revisão de literatura, variáveis relacionadas à sofisticação da organização logística e aos principais motivos relacionados à decisão de terceirização. Foram enviados questionários para 218 empresas do setor industrial, listadas no Ranking da Revista Exame. A partir dos 93 questionários recebidos, foi possível identificar dois grupos distintos de empresas e suas diferentes motivações para a terceirização: (1) empresas com maiores níveis de formalização organizacional e baixos níveis de adoção de tecnologias de informação; e (2) empresas com menores níveis de formalização organizacional e adoção intensiva de tecnologias de informação. Os resultados são discutidos sob o prisma de oportunidades para um posicionamento mais adequado dos prestadores de serviço logístico, na oferta de seus serviços a estes dois grupos de empresas.

Palavras-chave: terceirização, logística, motivadores, empresas brasileiras.

\section{Introdução}

O gerenciamento de cadeias de suprimento inclui um conjunto de processos de negócio que em muito ultrapassa as atividades diretamente relacionadas com a logística (Lambert e Stock, 1998). No entanto, a logística é um dos principais processos para o gerenciamento de cadeias de suprimento, pois existe uma clara e definitiva necessidade de integração dos fluxos de produto, de informação e dos fluxos financeiros (Bowersox, Closs e Stank, 1999). O desenvolvimento de novos produtos é, talvez, o exemplo mais óbvio dessa necessidade, pois vários aspectos do negócio devem ser incluídos nessa atividade: marketing, para estabelecer o conceito; pesquisa e desenvolvimento, para o projeto do produto; produção e logística, para executar as operações; e finanças, para a estruturação do projeto de investimento.
Para melhor compreender o conceito de gerenciamento de cadeias de suprimento, é fundamental entender o conceito de canal de distribuição já bastante consolidado e há muito utilizado por marketing. O canal de distribuição pode ser definido como o conjunto de unidades organizacionais, instituições e agentes que dão apoio à comercialização de produtos e de serviços de uma determinada empresa (Figueiredo, Fleury e Wanke, 2003).

Entre as funções de suporte à comercialização incluemse compras, vendas, transporte, armazenagem, produção e finanças. Qualquer unidade organizacional que execute uma ou mais funções de suporte é considerada membro do canal de distribuição. Os membros do canal de distribuição são classificados em dois grupos: membros primários e membros secundários. Os membros primários são os fabricantes, atacadistas e varejistas, por exemplo, que incorrem nos riscos derivados da posse de estoques. 
Os membros secundários são os prestadores de serviço como, por exemplo, os transportadores, armazenadores e os operadores logísticos, que não possuem a propriedade dos estoques.

A crescente quantidade de membros trabalhando num ambiente competitivo e de pouca coordenação é a principal razão para o crescimento dos custos. A solução para esse problema passa, necessariamente, pela busca de maior coordenação e sincronização por meio de troca de informações (Figueiredo, Fleury e Wanke, 2003). O avanço da informática, combinado com a revolução das telecomunicações criou as condições para a coordenação eficiente entre empresas. O gerenciamento da cadeia de suprimentos é, na realidade, o esforço de integração dos diversos membros do canal de distribuição, pela administração compartilhada de diferentes processos-chave de negócio.

O sucesso de qualquer arranjo operacional numa cadeia de suprimentos depende diretamente do componente logístico. Alcançar a excelência nas operações logísticas, ou seja, a capacidade de uma empresa, simultaneamente, reduzir custos e melhorar níveis de serviço, tem sido objeto de diversas pesquisas ao longo dos últimos quinze anos (Bowersox, Closs e Stank, 1999). Essas pesquisas indicam uma forte correlação entre excelência operacional e o grau de sofisticação da organização logística. Mais especificamente, essas pesquisas revelaram que a sofisticação da organização logística de uma empresa é refletida em diversos fatores como (1) a ênfase no planejamento, no monitoramento de desempenho e no contínuo investimento em tecnologias de informação (TIs); (2) o comprometimento no estabelecimento de relacionamentos cooperativos com clientes, fornecedores e prestadores de serviço; e (3) a formalização e integração organizacional das diferentes atividades logísticas.

Percebe-se que os fatores, que levam à excelência operacional em logística, podem ser internos à empresa, como a formalização organizacional, a mensuração de desempenho e a adoção de TIs; ou externos, como o desenvolvimento de relações cooperativas com outros membros da cadeia. Especificamente, com relação aos fatores externos, a contratação dos serviços de operadores logísticos tem evoluído rapidamente, no Brasil e no mundo (Figueiredo, Fleury e Wanke, 2003). Existem diversas motivações para terceirizar as atividades logísticas, podendo ir desde a redução de custos e do investimento em ativos até a aquisição de maior flexibilidade nas operações logísticas e a expansão dos mercados. Há, também, circunstâncias em que a terceirização das atividades logísticas é o meio para aprimorar as tecnologias de informação utilizadas.

Estas inúmeras possibilidades aumentam a importância de segmentar as motivações, para a terceirização das atividades logísticas por diferentes grupos de embarca- dores, ou seja, de empresas que utilizam recursos físicos para operacionalizar suas atividades. Por exemplo, é possível que embarcadores mais sofisticados em determinadas dimensões da organização logística tendam a buscar maior flexibilidade operacional e a expansão de mercados, ao passo que embarcadores menos sofisticados em determinadas dimensões tendam a buscar reduções de custo.

Esta pesquisa tem por objetivo principal auxiliar os operadores logísticos brasileiros a identificar os diferentes grupos de embarcadores do setor industrial e suas respectivas motivações, para a terceirização das atividades logísticas. Em primeiro lugar, pelo entendimento da relação entre as diferentes dimensões de sofisticação da organização logística e as motivações para a terceirização, por parte dos embarcadores. Em segundo lugar, pelo agrupamento dos embarcadores a partir de semelhanças verificadas nas diferentes dimensões de sofisticação da organização logística. Conforme comentado, diferentes grupos de embarcadores podem apresentar diferentes motivações para a terceirização das atividades logísticas. Estes grupos, entretanto, podem ser mais ou menos sofisticados em diferentes dimensões da organização logística.

\section{Sofisticação da Organização Logística}

O modelo conceitual de sofisticação da organização logística (Figura 1) utilizado nesta pesquisa é o apresentado por Lavalle e Fleury (2000), que constitui uma extensão do modelo desenvolvido por Bowersox e Daugherty (1992). De acordo com o modelo, a sofisticação logística pode ser decomposta em três dimensões: grau de formalização organizacional, uso de tecnologia de informação e índices de monitoramento de desempenho.

$\mathrm{O}$ grau de formalização organizacional refere-se ao posicionamento do principal executivo de logística na estrutura organizacional da empresa. Tradicionalmente, a responsabilidade pelas atividades logísticas sempre foi fragmentada e dispersa (Van Amstel e Starreveld, 1993) e o nível hierárquico dos responsáveis por estas atividades sempre foi baixo, implicando em pequeno grau de coordenação. Uma maior sofisticação logística seria, em parte, reflexo do posicionamento do executivo responsável pela logística nos níveis mais elevados da hierarquia organizacional, o que permitiria, em parte, o gerenciamento integrado das diversas atividades e a escolha eficiente dos trade-offs existentes: estoques $v s$. transporte, estoques $v s$. armazenagem, transportes vs. Armazenagem, etc (Lambert e Stock, 1998).

A tecnologia de informação está associada à abrangência de utilização de softwares e demais tecnologias de apoio para a tomada de decisão em diferentes atividades logísticas. Segundo Lavalle e Fleury (2000), "a tecnolo- 


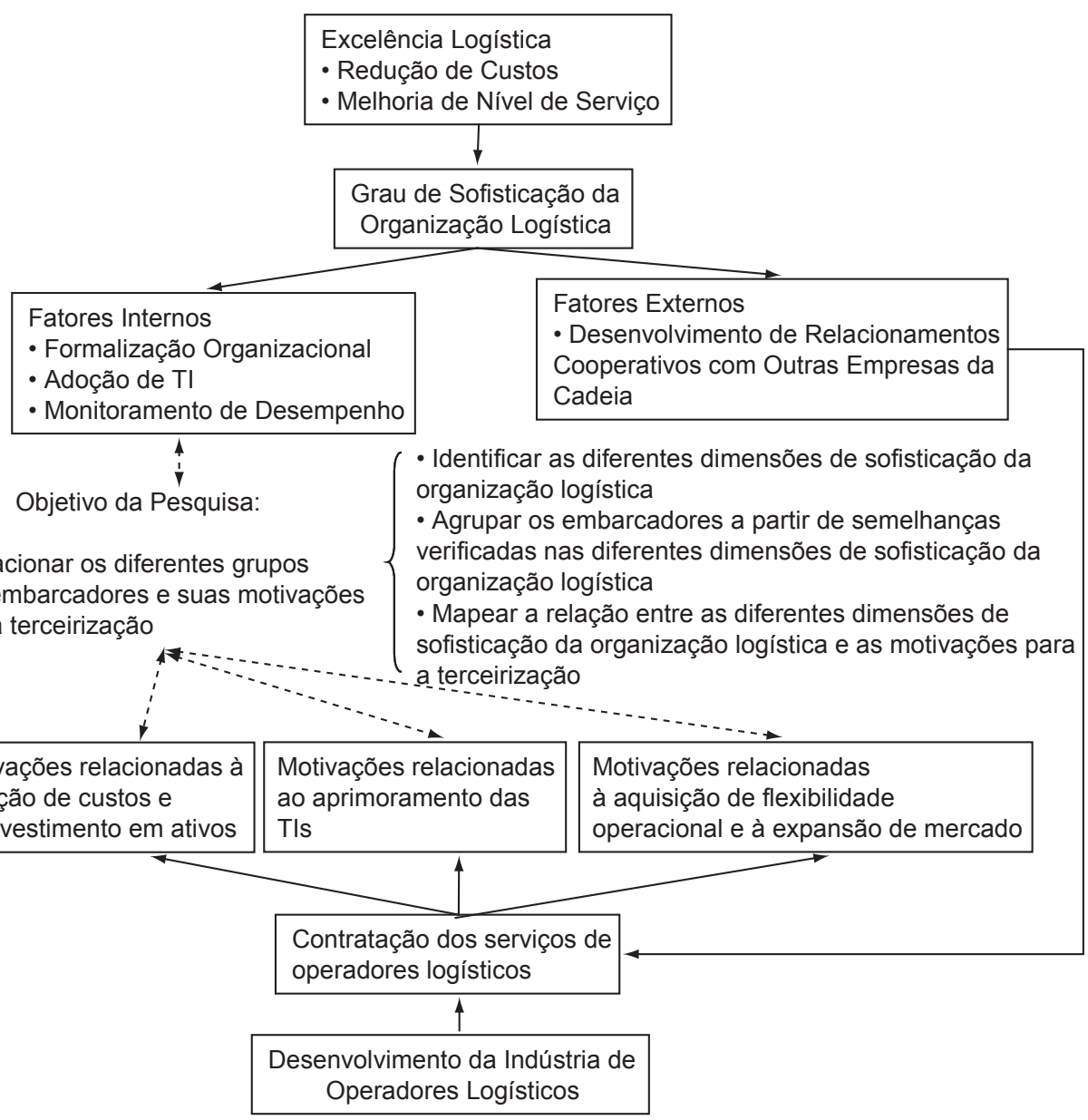

Figura 1. Fluxograma Conceitual da Pesquisa.

gia de informação viabiliza a coleta, análise e transmissão de grandes quantidades de informações operacionais e gerenciais precisas em tempo hábil, permitindo maior agilidade no processo decisório". Quando um processo decisório é mais ágil, os ciclos operacionais são mais curtos e as adaptações menos traumáticas.

Finalmente, o monitoramento de desempenho referese ao controle sistemático das atividades logísticas, peça chave ao seu aperfeiçoamento contínuo. De acordo com Lavalle e Fleury (2000), "a análise sistemática de indicadores de desempenho associados a custos e serviço ao cliente resulta em maior conhecimento das atividades como um todo que, por seu turno, possibilita maior flexibilidade das operações".

\section{Motivações para a Terceirização de Atividades Logísticas}

Nesta pesquisa, as motivações para a terceirização de atividades logísticas são analisadas em duas dimensões distintas, a partir da perspectiva dos embarcadores do setor industrial. São elas: (1) possíveis motivos para terceirizar as atividades logísticas; e (2) possíveis motivos para não aumentar a terceirização em logística, dado que a empresa já terceiriza parte ou a totalidade de suas atividades.

De acordo com Fleury e Ribeiro (2001), a contratação dos serviços de operadores logísticos vem crescendo muito rapidamente em todo o mundo e, por conseqüência, também no Brasil. Especificamente, de acordo com Wanke (1998) e com Figueiredo, Fleury e Wanke (2003), os possíveis motivos para terceirizar as atividades logísticas podem estar relacionados (1) à focalização no core business; (2) à redução de custos; (3) à redução no investimento em ativos; (4) ao aumento dos níveis de serviço logístico prestado aos clientes; (5) ao aumento do controle das atividades logísticas; (6) à aquisição de maior flexibilidade nas operações logísticas; (7) à busca de maior eficiência na execução de atividades operacionais; (8) à busca de maior know-how para a geração de novas soluções logísticas; (9) à melhoria de TIs utilizadas; e (10) à expansão dos mercados.

Por outro lado, Sink e Langley (1996 e 1997), Wanke (1998), Fleury e Ribeiro (2001) e Figueiredo, Fleury e Wanke (2003) apontam que os possíveis motivos para não aumentar a terceirização em logística, dado que uma em- 
presa terceiriza parte ou a totalidade de suas atividades, podem estar relacionados (1) à importância estratégica da logística; (2) à não redução dos custos totais; (3) aos elevados preços cobrados pelos operadores logísticos; (4) à não redução dos ativos próprios da empresa; (5) ao não atingimento dos níveis de serviço desejados; (6) à não diminuição do tempo e esforço gerencial gastos com a logística; (7) à perda do controle das atividades logísticas; (8) à perda da flexibilidade nas operações logísticas; (9) à maior capacitação por parte da empresa na execução de atividades operacionais; (10) à maior capacidade de proposição de novas soluções logísticas; (11) à não utilização de TIs adequadas por parte dos operadores logísticos; (12) à necessidade de divulgar informações confidenciais da empresa; (13) às dificuldades no relacionamento com o prestador de serviço; e (14) à não avaliação da possibilidade de aumentar a terceirização logística.

\section{Principais Perguntas e Metodologia de Pesquisa}

Com base na revisão da literatura, foram formuladas quatro perguntas principais de pesquisa. A primeira pergunta está relacionada à identificação das dimensões de sofisticação da organização logística para os embarcadores brasileiros, a partir de dados empíricos. A pergunta pode ser formalizada como se segue:

1. É possível identificar as diferentes dimensões de sofisticação da organização logística, extraídas a partir de variáveis que refletem a formalização organizacional, o uso de tecnologia de informação e a mensuração de desempenho? Em caso afirmativo, quais são estas dimensões?

A segunda pergunta está relacionada ao agrupamento dos embarcadores brasileiros do setor industrial, a partir de semelhanças verificadas nas diferentes dimensões de sofisticação da organização logística, identificadas na primeira questão:

2. Quantos e quais são os grupos de embarcadores formados a partir de semelhanças nas diferentes dimensões de sofisticação da organização logística? Qual a justificativa teórica para estes grupos? Quais os seus níveis de significância estatística?

As últimas duas perguntas estão relacionadas à determinação de relações entre as diferentes dimensões de sofisticação da organização logística, os possíveis motivos para terceirizar as atividades logísticas e os possíveis motivos para não aumentar a terceirização. Estas perguntas são apresentadas a seguir:

3. Diferentes dimensões de sofisticação estão relacionadas a diferentes motivações para terceirização? Em caso afirmativo, quais as relações e quais os seus níveis de significância estatística?
4. Diferentes dimensões de sofisticação estão relacionadas a diferentes motivações para não aumentar a terceirização? Em caso afirmativo, quais as relações e quais os seus níveis de significância estatística?

Foram selecionadas a partir do ranking das 500 maiores da Revista Exame, todas as empresas do setor secundário/indústrias (340 empresas). Durante o período de março a julho de 2003, foram enviados 218 questionários para os gerentes de logística destas empresas, sendo que 93 destinatários retornaram os questionários. Isto perfaz uma taxa de resposta de $42,7 \%$, com relação aos questionários enviados, e de $27,3 \%$, com relação à população inicialmente considerada (empresas do setor secundário, listadas no ranking da Revista Exame).

Com relação à primeira pergunta da pesquisa, foram investigadas dezenove variáveis, possivelmente relacionadas à sofisticação logística dos embarcadores brasileiros do setor industrial, ou seja, relacionadas à formalização organizacional, ao uso de tecnologia de informação e à mensuração de desempenho. Estas variáveis, sua operacionalização e suas escalas são apresentadas na Tabela 1.

Para a identificação das diferentes dimensões de sofisticação relacionadas aos embarcadores brasileiros do setor industrial, foi utilizada a técnica de Análise Fatorial nestas dezenove variáveis. A Análise Fatorial é recomendada para os casos nos quais se deseja determinar diferentes fatores ou dimensões a partir das variáveis observadas, tendo como base um construto teórico. Neste caso, o construto teórico é a sofisticação da organização logística.

Com relação à segunda pergunta da pesquisa, foi utilizada a técnica de Análise de Cluster nas 93 empresas pesquisadas. Em função do caráter exploratório do estudo, estas empresas foram subdivididas em apenas dois grupos, para permitir melhor interpretação dos resultados em virtude da insuficiência de referencial teórico sobre o assunto.

Já, com relação à terceira e à quarta perguntas da pesquisa, foram investigados, respectivamente, os 10 possíveis motivos para terceirizar as atividades logísticas e os 14 possíveis motivos para não aumentar a terceirização em logística, todos apresentados anteriormente na revisão de literatura. $\mathrm{O}$ estabelecimento de relações, entre estes diferentes motivos e as diferentes dimensões de sofisticação da organização logística, foi feito por Análise de Regressão Logística Simples. Esta técnica é preferível à Análise Discriminante na separação de dois grupos de dados (apresentar ou não um determinado motivo), em função de um determinado critério (dimensão de sofisticação da organização logística), em virtude de sua maior flexibilidade. Sua utilização e interpretação são bastante intuitivas e análogas à Análise de Regressão Linear Simples (Kleinbaum, Kupper e Muller, 1998) e não há 
Tabela 1. Variáveis Relacionadas à Sofisticação Logística dos Embarcadores.

\begin{tabular}{|c|c|c|c|}
\hline Dimensão & Variáveis Pesquisadas & Escala Adotada & Tipo de Escala \\
\hline Formalização Organizacional & $\begin{array}{l}1 \text { - Nível hierárquico do principal executivo em } \\
\text { logística }\end{array}$ & $\begin{array}{l}5=\text { Presidência } \\
4=\text { Diretoria } \\
3=\text { Gerência } \\
2=\text { Chefia } \\
1=\text { Outro nível }\end{array}$ & Ordinal \\
\hline $\begin{array}{l}\text { Tecnologia de Informação - uti- } \\
\text { lização de softwares ou tecnolo- } \\
\text { gias para suporte à decisão em } \\
\text { diferentes atividades logísticas }\end{array}$ & $\begin{array}{l}2 \text { - Rastreamento do veículo } \\
3 \text { - Roteirização } \\
4 \text { - Programação de entrega } \\
5 \text { - Rádio-freqüência } \\
6 \text { - Código de barras } \\
7 \text { - Separação } \\
8 \text { - Endereçamento } \\
9 \text { - Auditoria de frete } \\
10 \text { - Previsão de vendas } \\
11 \text { - Programação de compras } \\
12 \text { - Administração de fornecedores } \\
13 \text { - Status do carregamento } \\
14 \text { - EDI } \\
15 \text { - Sistema ERP } \\
16 \text { - Gerenciamento do estoque no cliente }\end{array}$ & $\begin{array}{l}1=\text { Sim } \\
0=\text { Não }\end{array}$ & Nominal (dummy) \\
\hline \multirow[t]{2}{*}{$\begin{array}{l}\text { Monitoramento de Desempenho } \\
\text { - acompanhamento do desem- } \\
\text { penho do operador logístico } \\
\text { em termos de custo e nível de } \\
\text { serviço }\end{array}$} & $\begin{array}{l}17 \text { - Freqüência de monitoramento com relação aos } \\
\text { custos } \\
18 \text { - Freqüência de monitoramento com relação ao } \\
\text { nível de serviço }\end{array}$ & $\begin{array}{l}5=\text { Diário/Semanal } \\
4=\text { Mensal/Bimestral } \\
3=\text { Semestral } \\
2=\text { Anual } \\
1=\text { Não monitora }\end{array}$ & Ordinal \\
\hline & 19 - Quantidade de indicadores monitorados & Variável inteira, $>=0$ & Razão \\
\hline
\end{tabular}

necessidade de assegurar a normalidade das matrizes de covariância dos dados, assim como ocorre na Análise Discriminante (Hair, Anderson e Tatham, 1998).

O nível máximo de significância considerado aceitável nesta pesquisa foi de 0,10 . De acordo com Mentzer e Flint (1997), níveis de significância entre 0,05 e 0,10 podem ser aceitos em pesquisas exploratórias em logística. Também deve ser destacado que a escolha dos métodos estatísticos empregados, para relacionar os diferentes motivos com as diferentes dimensões de sofisticação da organização logística, observou a natureza de suas escalas (Figura 2). Castro (1978) aponta para a crucial importância da compatibilidade entre as escalas das variáveis dependentes e os testes estatísticos. A operacionalização desses motivos e suas respectivas escalas são apresentadas na Tabela 2.

\section{Análise dos Resultados}

Com relação à primeira pergunta, a extração dos fatores principais das dezenove variáveis, possivelmente relacionadas à sofisticação da organização logística (cf. Tabela 1), foi conduzida por Análise Fatorial com rotação Varimax Normalizada, para a amostra com 93 observações. Os resultados são apresentados na Tabela 3, ape- nas para os fatores de carga acima de 0,50 e eigenvalues maiores que 1. Segundo Tabachnik e Fidell (2001), apenas os fatores de carga acima de 0,50 (25\% de sobreposição na variância) devem ser interpretados, podendo, nestes casos, ser afirmado que a variável representaria uma boa medida do fator. Dessa forma, seis fatores principais representam as diferentes dimensões de sofisticação da organização logística, interpretados como se segue:

- As variáveis utilização das tecnologias de Rádio-frequiência e de Código de barras e a utilização de softwares para a informação do Status do carregamento para o cliente compõem o fator 1 , interpretado como a Dimensão de Sofisticação no Rastreamento de Carregamentos (DSRC);

- As variáveis utilização de softwares de Programação de compras e de Administração de fornecedores e a utilização da tecnologia de EDI compõem o fator 2, interpretado como a Dimensão de Sofisticação no Relacionamento com Fornecedores (DSRF);

- As variáveis utilização de softwares de Separação e de Endereçamento compõem o fator 3, interpretado como a Dimensão de Sofisticação no Manuseio de Materiais (DSMM); 


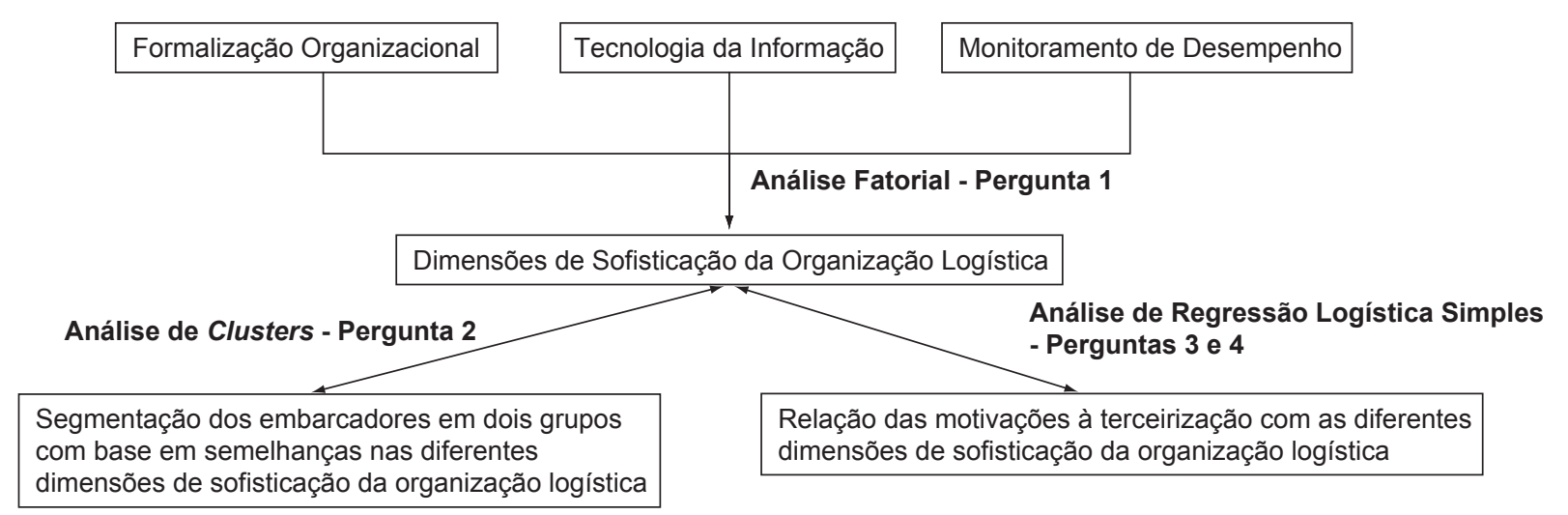

Figura 2. Relação entre as Principais Perguntas da Pesquisa e a Metodologia Adotada.

Tabela 2. Motivações Relacionadas à Terceirização de Atividades Logísticas.

\begin{tabular}{|c|c|c|c|}
\hline Dimensão & Variáveis Pesquisadas & Escala Adotada & $\begin{array}{l}\text { Tipo de } \\
\text { Escala }\end{array}$ \\
\hline $\begin{array}{l}\text { Possíveis motivos para } \\
\text { terceirizar as atividades } \\
\text { logísticas }\end{array}$ & $\begin{array}{l}1 \text { - Focar no core business } \\
2 \text { - Reduzir custos } \\
3 \text { - Reduzir o investimento em ativos } \\
4 \text { - Aumentar os níveis de serviço logístico } \\
5 \text { - Aumentar o controle das atividades logísticas } \\
6 \text { - Adquirir maior flexibilidade nas operações logísticas } \\
7 \text { - Trazer para a empresa maior eficiência na execução das ativida- } \\
\text { des operacionais } \\
8 \text { - Trazer para a empresa maior know-how na geração de novas } \\
\text { soluções logísticas } \\
9 \text { - Melhorar as TIs utilizadas } \\
10 \text { - Expandir mercados }\end{array}$ & $\begin{array}{l}1=\text { Sim }, \text { concordo } \\
0=\text { Não }, \text { discordo }\end{array}$ & $\begin{array}{l}\text { Nominal } \\
(\text { dummy })\end{array}$ \\
\hline $\begin{array}{l}\text { Possíveis motivos para } \\
\text { não aumentar a tercei- } \\
\text { rização das atividades } \\
\text { logísticas }\end{array}$ & $\begin{array}{l}11 \text { - A logística é muito importante para ser terceirizada } \\
12 \text { - Os custos totais não se reduziriam } \\
13 \text { - Os preços cobrados pelos prestadores de serviço logístico são } \\
\text { elevados } \\
14 \text { - A utilização de ativos da própria empresa não seria reduzida } \\
15 \text { - Os níveis de serviço logístico desejados poderiam não ser } \\
\text { atingidos } \\
16 \text { - O tempo e o esforço gerencial gastos com logística não dimi- } \\
\text { nuiriam } \\
17 \text { - A empresa poderia perder o controle das atividades logísticas } \\
18 \text { - A empresa poderia perder flexibilidade nas operações logísticas } \\
19 \text { - A empresa tem mais capacidade que os prestadores de serviço } \\
\text { logístico na execução de atividades operacionais } \\
20 \text { - A empresa tem maior capacidade para propor novas soluções } \\
\text { logísticas } \\
21 \text { - Os prestadores de serviço logístico não utilizam TI adequada } \\
22 \text { - Seria necessário divulgar informações confidenciais da empresa } \\
23 \text { - Possíveis dificuldades no relacionamento entre a empresa e o } \\
\text { prestador de serviço logístico } \\
24 \text { - A possibilidade de aumento da terceirização não foi totalmente } \\
\text { avaliada }\end{array}$ & $\begin{array}{l}1=\text { Sim }, \text { concordo } \\
0=\text { Não }, \text { discordo }\end{array}$ & $\begin{array}{l}\text { Nominal } \\
\text { (dummy) }\end{array}$ \\
\hline
\end{tabular}

- As variáveis Monitoramento de custos e Monitoramento de nível de serviço do operador logístico compõem o fator 4, interpretado como a Dimensão de Sofisticação no Monitoramento de Desempenho (DSMD);
- As variáveis utilização de software de Roteirização e a utilização de Sistema ERP compõem o fator 5, interpretado como a Dimensão de Sofisticação na Programação das Operações (DSPO); e 
Tabela 3. Resultados da Extração dos Fatores Principais da Sofisticação Logística.

\begin{tabular}{|c|c|c|c|c|c|}
\hline $\begin{array}{c}\text { Fator } 1 \\
\text { Dimensão de } \\
\text { Sofisticação no } \\
\text { Rastreamento } \\
\text { de Carregamen- } \\
\text { tos } \\
\end{array}$ & $\begin{array}{c}\text { Fator } 2 \\
\text { Dimensão de } \\
\text { Sofisticação no } \\
\text { Relacionamento } \\
\text { com Fornece- } \\
\text { dores } \\
\end{array}$ & $\begin{array}{c}\text { Fator } 3 \\
\text { Dimensão de } \\
\text { Sofisticação no } \\
\text { Manuseio de } \\
\text { Materiais }\end{array}$ & $\begin{array}{c}\text { Fator } 4 \\
\text { Dimensão de } \\
\text { Sofisticação no } \\
\text { Monitoramento } \\
\text { de Desempenho }\end{array}$ & $\begin{array}{c}\text { Fator } 5 \\
\text { Dimensão de } \\
\text { Sofisticação na } \\
\text { Programação } \\
\text { das Operações }\end{array}$ & $\begin{array}{c}\text { Fator } 6 \\
\text { Dimensão de } \\
\text { Sofisticação na } \\
\text { Formalização } \\
\text { Organizacional }\end{array}$ \\
\hline $\begin{array}{l}\text { Rádio-freqüiência } \\
(0,77 ; 0,46 ; 0,74)\end{array}$ & $\begin{array}{l}\text { Programação de } \\
\text { compras } \\
(0,66 ; 0,30 ; 0,69)\end{array}$ & $\begin{array}{l}\text { Separação } \\
(0,73 ; 0,38 ; 0,85)\end{array}$ & $\begin{array}{l}\text { Desempenho de } \\
\text { custos } \\
(0,67 ; 0,33 ; 0,60)\end{array}$ & $\begin{array}{l}\text { Roteirização } \\
(0,51 ; 0,21 ; 0,50)\end{array}$ & $\begin{array}{l}\text { Nível hierárquico } \\
\text { do principal exe- } \\
\text { cutivo } \\
(0,89 ; 1,13 ; 0,94)\end{array}$ \\
\hline $\begin{array}{l}\text { Código de barras } \\
(0,70 ; 0,19 ; 0,68)\end{array}$ & $\begin{array}{l}\text { Administração de } \\
\text { fornecedores } \\
(0,74 ; 0,53 ; 0,68)\end{array}$ & $\begin{array}{l}\text { Endereçamento } \\
(0,85 ; 0,69 ; 0,83)\end{array}$ & $\begin{array}{l}\text { Desempenho de } \\
\text { serviço } \\
(0,77 ; 0,50 ; 0,66)\end{array}$ & $\begin{array}{l}\text { Sistema ERP } \\
(0,59 ; 0,29 ; 0,39)\end{array}$ & \\
\hline $\begin{array}{l}\text { Status do carrega- } \\
\text { mento } \\
(0,68 ; 0,26 ; 0,56)\end{array}$ & $\begin{array}{l}\text { EDI } \\
(0,52 ; 0,05 ; 0,32)\end{array}$ & & & & \\
\hline \multicolumn{6}{|c|}{ Percentual da variância explicada pelo fator } \\
\hline $13,8 \%$ & $12,0 \%$ & $9,7 \%$ & $8,5 \%$ & $6,8 \%$ & $6,6 \%$ \\
\hline $\begin{array}{l}\text { KMO = 0,626 } \\
\text { Qui-quadrado = } 305 \\
\text { O primeiro valor en } \\
\text { O segundo valor en } \\
\text { O terceiro valor ent }\end{array}$ & $\begin{array}{l}9 \text { (Sig. }=, 000) \\
\text { parênteses represen } \\
\text { arênteses represen } \\
\text { arênteses represent }\end{array}$ & $\begin{array}{l}\text { ator de carga } \\
\text { oeficiente do fat } \\
\text { omunalidades d }\end{array}$ & $\begin{array}{l}\text { as variáveis pad } \\
\text { veis }\end{array}$ & las & \\
\hline
\end{tabular}

- Finalmente, a variável Nível hierárquico do principal executivo de logística na empresa se confunde com o fator 6, interpretado como a Dimensão de Sofisticação na Formalização Organizacional (DSFO).

As dimensões de sofisticação são calculadas a partir das variáveis padronizadas (subtraída da média e dividida pelo desvio-padrão):

- DSRC = 0,46 [Rádio-freqüência] + 0,19 [Código de barras $]+0,26$ [Status do carregamento];

- $\mathrm{DSRF}=0,30$ [Programação compras $]+0,53$ [Adm. Fornecedores] + 0,05 [EDI];

- $\mathrm{DSMM}=$ 0,38 [Separação] + 0,69 [Endereçamento];

- $\mathrm{DSMD}=0,33$ [Monitoramento de custos $]+0,50$ [Monitoramento de serviço];

- $\mathrm{DSPO}=0,21$ [Roteirização] + 0,29 [Sistema ERP]; e

- $\mathrm{DSFO}=1,13$ [Nível hierárquico].

Com relação à segunda pergunta, a divisão dos embarcadores em dois grupos com base em semelhanças nas diferentes dimensões de sofisticação da organização logística foi conduzida pela Análise de Clusters. Foram consideradas as seis dimensões de sofisticação apresentadas na Tabela 3 . De acordo com os resultados apresentados nas Tabelas 4 e 5, as dimensões de sofisticação que apresentam maior distância absoluta entre os centróides dos dois grupos são o rastreamento de carregamentos, o
Tabela 4. Centróides dos Grupos de Embarcadores (Clusters).

\begin{tabular}{lcc}
\hline \multicolumn{1}{c}{ Dimensões } & \multicolumn{2}{c}{ Grupo ou Cluster } \\
& $\mathbf{1}$ & $\mathbf{2}$ \\
\hline DSRC & $-0,85$ & 0,37 \\
DSRF & $-0,95$ & 0,41 \\
DSMM & $-0,89$ & 0,38 \\
DSMD & 0,05 & $-0,02$ \\
DSPO & $-0,62$ & 0,27 \\
DSFO & 0,38 & $-0,16$ \\
\hline
\end{tabular}

relacionamento com fornecedores, o manuseio de materiais, a programação de operações e a formalização organizacional. De acordo com a Tabela 5, não é possível distinguir os dois grupos formados, para maximizar as diferenças nas diversas dimensões de sofisticação, com relação ao monitoramento de desempenho.

Deve ser ressaltado que os resultados dos testes $\mathrm{F}$, apresentados na Tabela 5, devem ser empregados apenas para descrever geometricamente os grupos formados, já que estes foram formados para maximizar as diferenças nas diferentes dimensões consideradas. Os níveis de significância observados, portanto, não podem ser interpretados como testes da hipótese de igualdade de médias.

Os resultados apresentados na Tabela 4 permitem inferir que os embarcadores podem apresentar dois padrões 
evolutivos distintos em direção a uma maior sofisticação da organização logística. No primeiro grupo (28 casos), os embarcadores apresentam maiores níveis de formalização organizacional, ainda que não sejam intensivos na adoção de diferentes TIs. Já, no segundo grupo (65 casos) e de modo contrário, os embarcadores apresentam menores níveis de formalização organizacional, apesar da adoção intensiva de diferentes TIs para planejamento, controle e operacionalização de diferentes aspectos da logística.

Com relação à terceira pergunta, a relação dos diferentes motivos para terceirizar as atividades logísticas com as diferentes dimensões de sofisticação da organização logística foi conduzida por Análise de Regressão Logística Simples. A seguir são descritos os resultados apresentados na Tabela 6.

- O motivo expandir mercados é explicado pela formalização organizacional $(1,37 ; \mathrm{p}<0,01)$. $\mathrm{O}$ coeficiente positivo indica que maiores níveis de formalização organizacional estão significativamente relacionados a uma maior proporção de respostas afirmativas a este motivo. O modelo que relaciona estas duas variáveis é significativo a 0,001 , com valor de Qui-quadrado de 19,33 e poder explicativo de $30 \%$ (R-quadrado de Nagelkerke);

- O motivo adquirir maior flexibilidade nas operações logísticas é explicado, simultaneamente, pelo relacionamento com fornecedores $(-0,51 ; 0,08)$, pelo manuseio de materiais $(0,55 ; 0,05)$ e pela formalização organizacional $(0,66 ; 0,02)$. Os sinais dos coeficientes indicam que embarcadores com maiores níveis de formalização organizacional, com utilização intensiva de TIs no manuseio de materiais e menor sofisticação no relacionamento com fornecedores estão significativamente relacionados a uma maior proporção de respostas afirmativas a este motivo. $\mathrm{O}$ modelo que relaciona estas variáveis é significativo a 0,05 , com valor de Qui-quadrado de 12,50 e poder explicativo de $18 \%$ (R-quadrado de Nagelkerke);

- O motivo obter maior know-how para soluções logísticas é explicado, simultaneamente, pelo manuseio de materiais $(0,78 ; 0,01)$ e pelo monitoramento de desempenho $(-0,48 ; 0,07)$. Os sinais dos coeficientes indicam que embarcadores com utilização intensiva de

Tabela 5. Análise de Variância dos Grupos.

\begin{tabular}{lcccccc}
\hline \multicolumn{1}{c}{ Dimensão } & \multicolumn{2}{c}{ Grupo ou Cluster } & \multicolumn{2}{c}{ Erro } & F & Sig. \\
& $\begin{array}{c}\text { Média dos } \\
\text { Quadrados }\end{array}$ & $\begin{array}{c}\text { Graus de } \\
\text { Liberdade }\end{array}$ & $\begin{array}{c}\text { Média dos } \\
\text { Quadrados }\end{array}$ & $\begin{array}{c}\text { Graus de } \\
\text { Liberdade }\end{array}$ & & \\
\hline DSRC & 29,160 & 1 & 0,691 & 91 & 42,228 & 0,000 \\
DSRF & 36,396 & 1 & 0,611 & 91 & 59,564 & 0,000 \\
DSMM & 31,451 & 1 & 0,665 & 91 & 47,268 & 0,000 \\
DSMD & 0,103 & 1 & 1,010 & 91 & 0,102 & 0,750 \\
DSPO & 15,220 & 1 & 0,844 & 91 & 18,039 & 0,000 \\
DSPO & 5,698 & 1 & 0,948 & 91 & 6,009 & 0,016 \\
\hline
\end{tabular}

Tabela 6. Resumo dos Resultados das Análises de Regressão Logística Simples para os Diferentes Motivos em Função das Dimensões de Sofisticação*.

\begin{tabular}{|c|c|c|c|c|c|c|c|c|c|c|c|c|c|c|}
\hline \multirow{2}{*}{$\begin{array}{l}\text { Possíveis Moti- } \\
\text { vos para Tercei- } \\
\text { rizar Atividades } \\
\text { Logísticas** }\end{array}$} & \multicolumn{2}{|c|}{ Modelo } & \multicolumn{2}{|c|}{ DSRF } & \multicolumn{2}{|c|}{ DSMM } & \multicolumn{2}{|c|}{ DSMD } & \multicolumn{2}{|c|}{ DSPO } & \multicolumn{2}{|c|}{ DSFO } & \multicolumn{2}{|c|}{ DSRC } \\
\hline & quadrado & Sig. & B & Sig. & B & Sig. & B & Sig. & B & Sig. & B & Sig. & B & Sig. \\
\hline $1-(8 \%)$ & 5,33 & 0,50 & 0,39 & 0,15 & $(0,43)$ & 0,19 & 0,44 & 0,11 & 0,16 & 0,54 & $(0,04)$ & 0,89 & $(0,02)$ & 0,93 \\
\hline $2-(18 \%)$ & 10,37 & 0,11 & 0,34 & 0,27 & 0,18 & 0,61 & $(0,56)$ & 0,08 & 0,08 & 0,80 & $(0,82)$ & 0,04 & $(0,12)$ & 0,73 \\
\hline $3-(8 \%)$ & 5,37 & 0,50 & $(0,00)$ & 1,00 & $(0,12)$ & 0,65 & $(0,08)$ & 0,75 & 0,45 & 0,06 & 0,18 & 0,44 & $(0,12)$ & 0,64 \\
\hline $4-(6 \%)$ & 4,62 & 0,59 & $(0,23)$ & 0,35 & 0,31 & 0,22 & 0,29 & 0,21 & $(0,15)$ & 0,52 & 0,03 & 0,88 & 0,03 & 0,90 \\
\hline $5-(3 \%)$ & 2,28 & 0,89 & 0,14 & 0,59 & 0,27 & 0,33 & 0,13 & 0,58 & $(0,09)$ & 0,71 & $(0,00)$ & 0,99 & $(0,27)$ & 0,32 \\
\hline $6-(18 \%)$ & 12,50 & 0,05 & $(0,51)$ & $\mathbf{0 , 0 8}$ & 0,55 & 0,05 & 0,15 & 0,54 & $(0,30)$ & 0,27 & 0,66 & $\mathbf{0 , 0 2}$ & 0,28 & 0,32 \\
\hline $7-(7 \%)$ & 4,70 & 0,58 & 0,06 & 0,80 & 0,21 & 0,42 & 0,09 & 0,69 & $(0,41)$ & 0,07 & 0,14 & 0,55 & 0,19 & 0,44 \\
\hline $8-(17 \%)$ & 12,65 & 0,05 & $(0,06)$ & 0,81 & 0,78 & 0,01 & $(0,48)$ & $\mathbf{0 , 0 7}$ & $(0,16)$ & 0,52 & 0,38 & 0,12 & $(0,42)$ & 0,15 \\
\hline $9-(14 \%)$ & 10,00 & 0,12 & $(0,33)$ & 0,23 & 0,85 & 0,01 & 0,16 & 0,52 & $(0,04)$ & 0,87 & 0,17 & 0,47 & $(0,02)$ & 0,95 \\
\hline $10-(30 \%)$ & 19,83 & $\mathbf{0 , 0 0}$ & $(0,15)$ & 0,62 & 0,23 & 0,48 & 0,13 & 0,67 & 0,42 & 0,19 & 1,37 & 0,00 & 0,06 & 0,85 \\
\hline
\end{tabular}

*Os resultados significativos estão marcados em negrito e a numeração dos motivos corresponde à Tabela 2

**Os valores entre parênteses correspondem ao R-quadrado de Nagelkerke 
TIs no manuseio de materiais e com baixos níveis de monitoramento de desempenho estão significativamente relacionados a uma maior proporção de respostas afirmativas a este motivo. $\mathrm{O}$ modelo que relaciona estas variáveis é significativo a 0,05 , com valor de Qui-quadrado de 12,65 e poder explicativo de $17 \%$ (R-quadrado de Nagelkerke);

- O motivo reduzir custos é explicado pela formalização organizacional $(-0,82 ; 0,04)$ e pelo monitoramento de desempenho $(-0,56 ; 0,08)$. Os sinais dos coeficientes indicam que embarcadores com menores níveis de formalização organizacional e de monitoramento de desempenho estão significativamente relacionados a uma maior proporção de respostas afirmativas a este motivo;

- O motivo melhorar as tecnologias de informação utilizadas é explicado apenas pelo manuseio de materiais $(0,85 ; 0,01)$. $\mathrm{O}$ sinal do coeficiente indica que embarcadores com utilização intensiva de TIs no manuseio de materiais estão significativamente relacionados a uma maior proporção de respostas afirmativas a este motivo;

- O motivo reduzir o investimento em ativos é explicado apenas pela programação das operações $(0,45 ; 0,06)$. O sinal do coeficiente indica que embarcadores com utilização intensiva de TIs para a programação das operações estão significativamente relacionados a uma maior proporção de respostas afirmativas a este motivo; e

- Finalmente, o motivo obter maior eficiência na execução de atividades operacionais é explicado apenas pela programação das operações $(-0,41 ; 0,07)$. O sinal do coeficiente indica que embarcadores com baixos níveis de adoção de TIs para a programação das operações estão significativamente relacionados a uma maior proporção de respostas afirmativas a este motivo.

Com relação à quarta pergunta, a relação dos diferentes motivos, para não aumentar a terceirização de atividades logísticas com as diferentes dimensões de sofisticação da organização logística, foi conduzida por Análise de Regressão Logística Simples. A seguir, são descritos os resultados apresentados na Tabela 7.

- O motivo a empresa tem maior capacidade na execução de atividades operacionais é explicado, simultaneamente, pela formalização organizacional $(1,08 ; 0,00)$ e pelo rastreamento de carregamentos $(0,76 ; 0,02)$. Os sinais dos coeficientes indicam que embarcadores com maiores níveis de formalização organizacional e com utilização intensiva de TIs, no rastreamento de carregamentos, estão significativamente relacionados a uma maior proporção de respostas afirmativas a este motivo. O modelo que relaciona estas variáveis é significativo a 0,01, com valor de Qui-quadrado de 17,56 e poder explicativo de $26 \%$ (R-quadrado de Nagelkerke);

- O motivo seria necessário divulgar informações con-

Tabela 7. Resumo dos Resultados das Análises de Regressão Logística Simples para os Diferentes Motivos em Função das Dimensões de Sofisticação*.

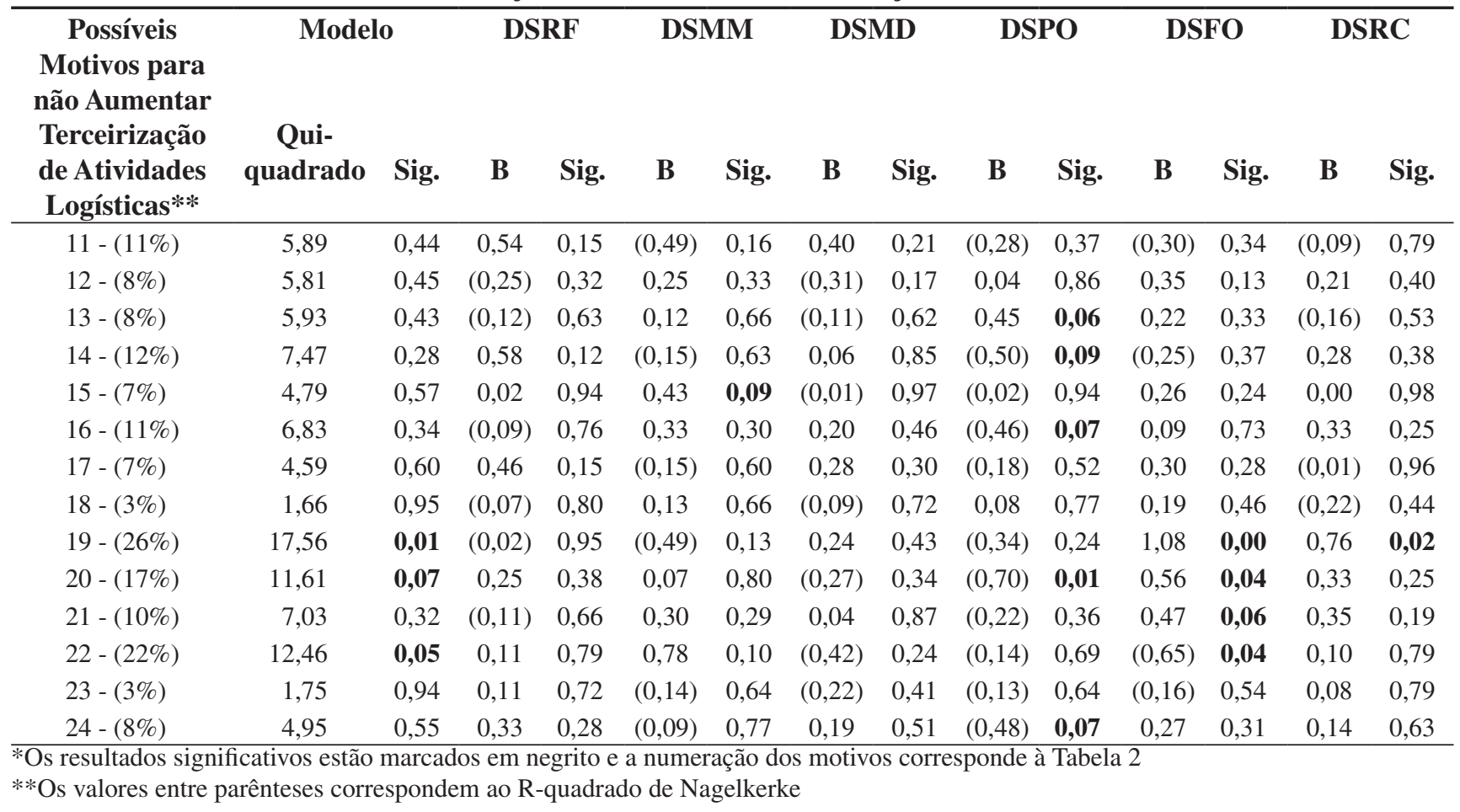


fidenciais da empresa é explicado pela formalização organizacional $(-0,65 ; 0,04)$. O sinal do coeficiente indica que embarcadores com menores níveis de formalização organizacional estão significativamente relacionados a uma maior proporção de respostas afirmativas a este motivo. O modelo que relaciona estas variáveis é significativo a 0,05 , com valor de Qui-quadrado de 12,46 e poder explicativo de $22 \%$ (R-quadrado de $\mathrm{Na}-$ gelkerke);

- O motivo a empresa tem maior capacidade de propor soluções logísticas é explicado, simultaneamente, pela formalização organizacional $(0,56 ; 0,04)$ e pela programação de operações $(-0,70 ; 0,01)$. Os sinais dos coeficientes indicam que embarcadores com maiores níveis de formalização organizacional e com menores níveis de adoção de TIs, para a programação de operações, estão significativamente relacionados a uma maior proporção de respostas afirmativas a este motivo. O modelo que relaciona estas variáveis é significativo a 0,07 , com valor de Qui-quadrado de 11,61 e poder explicativo de 17\% (R-quadrado de Nagelkerke);

- O motivo os preços cobrados pelos prestadores de serviço são elevados é explicado apenas pela programação de operações $(0,45 ; 0,06)$. $\mathrm{O}$ sinal do coeficiente indica que embarcadores com utilização intensiva de TIs, para a programação de operações, estão significativamente relacionados a uma maior proporção de respostas afirmativas a este motivo;

- O motivo a utilização de ativos próprios não seria reduzida é explicado apenas pela programação de operações $(-0,50 ; 0,09)$. O sinal do coeficiente indica que embarcadores com menores níveis de adoção de TIs, para a programação de operações, estão significativamente relacionados a uma maior proporção de respostas afirmativas a este motivo;

- O motivo o tempo e o esforço gerencial gastos com logística não diminuiriam é explicado apenas pela programação de operações $(-0,46 ; 0,07)$. O sinal do coeficiente indica que embarcadores com menores níveis de adoção de TIs, para a programação de operações, estão significativamente relacionados a uma maior proporção de respostas afirmativas a este motivo;

- O motivo a possibilidade de aumento da terceirização logística não foi totalmente avaliada é explicado apenas pela programação de operações $(-0,48 ; 0,07)$. O sinal do coeficiente indica que embarcadores com menores níveis de adoção de TIs, para a programação de operações, estão significativamente relacionados a uma maior proporção de respostas afirmativas a este motivo;

- O motivo os níveis de serviço logístico desejados poderiam não ser atendidos é explicado apenas pelo manuseio de materiais $(0,43 ; 0,09)$. O sinal do coeficiente indica que embarcadores com utilização intensiva de
TIs no manuseio de materiais estão significativamente relacionados a uma maior proporção de respostas afirmativas a este motivo; e

- Finalmente, o motivo os prestadores de serviço logístico não utilizam TI adequada é explicado apenas pela formalização organizacional $(0,47 ; 0,06)$. O sinal do coeficiente indica que embarcadores com maiores níveis de formalização organizacional estão significativamente relacionados a uma maior proporção de respostas afirmativas a este motivo.

\section{Discussão dos Resultados}

Os resultados da pesquisa constituem avanços no aspecto teórico e no aspecto prático da tomada de decisões. No campo teórico, foram identificadas as dimensões de sofisticação da organização logística para o agrupamento dos embarcadores em função de semelhanças na adoção de tecnologias de informação, na formalização organizacional e no monitoramento de desempenho. Também foi possível relacionar as diferentes dimensões de sofisticação da organização logística aos diferentes motivos para terceirizar as atividades logísticas e, também, aos motivos para não aumentar a terceirização em logística.

No aspecto prático da tomada de decisões, os resultados da pesquisa refletem as motivações de dois grupos de embarcadores brasileiros com relação à terceirização de atividades logísticas. Esses resultados poderiam ser empregados pelos operadores logísticos tanto na definição de seu posicionamento estratégico, ou seja, na oferta de pacotes de serviços específicos para grupos de clientes específicos, quanto na determinação de iniciativas de capacitação interna, que poderiam ser adotadas visando maior especialização e customização de serviços. Mais especificamente, os resultados encontrados também permitem elencar uma série de proposições sobre os grupos de embarcadores e suas motivações para a terceirização de atividades logísticas.

Os embarcadores do primeiro grupo - maiores níveis de formalização organizacional e baixos níveis de adoção de TIs - estão motivados à terceirização como forma de adquirir maior flexibilidade nas operações logísticas, permitindo a expansão de seus mercados. A busca por flexibilidade não se concentra apenas nas atividades de distribuição, mas também nas atividades de suprimento, principalmente em função dos baixos níveis de adoção de TIs no relacionamento com fornecedores. Além da flexibilidade nas atividades de suprimento e de distribuição, os embarcadores do primeiro grupo também buscam maior eficiência na execução de atividades operacionais, sobretudo na programação de atividades internas à empresa como, por exemplo, compras, produção e roteirização (Figura 3).

Eventualmente, os embarcadores do primeiro grupo 
estariam dispostos a contratar, por preços mais elevados, atividades de suprimento e de distribuição mais flexíveis que as atualmente desempenhadas pela empresa. Por outro lado, a contratação de prestadores de serviço estaria limitada a um papel auxiliar na execução das atividades internas, podendo envolver a implementação de novas tecnologias de informação no controle de estoques, na armazenagem e na movimentação interna. Este papel auxiliar visaria assegurar maior eficiência operacional e, não obstante, poderia envolver a contratação de pessoal terceirizado para essas atividades.

Os embarcadores do segundo grupo - menores níveis de formalização organizacional e adoção intensiva de TIs - estão motivados à terceirização de atividades logísticas como iniciativa gerencial ou primeiro passo para a redução de custos. Além da redução de custos, os embarcadores do segundo grupo também buscam a redução do investimento em ativos, especificamente na programação de atividades internas como compras, produção e roteirização. Estes embarcadores se destacam pela adoção intensiva de TIs no manuseio de materiais - sobretudo na separação e no manuseio para a distribuição aos mercados. Apesar da adoção intensiva de TI no manuseio de materiais, há uma preocupação constante com a melhoria contínua das tecnologias empregadas e sua adequada utilização na geração de novas soluções logísticas e, conseqüentemente, maior flexibilidade na distribuição aos mercados (Figura 4).

Eventualmente, os embarcadores do segundo grupo es- tariam dispostos a terceirizar as atividades de suprimento dos fornecedores e partes ou a totalidade das atividades internas de compras, produção e roteirização como forma de redução de custos e do investimento em ativos. Por outro lado, a contratação externa de partes das atividades de separação, endereçamento e distribuição aos mercados poderia ocorrer como forma de assegurar melhoria contínua e flexibilidade. Assim como os embarcadores do primeiro grupo, também haveria predisposição à contratação dessas atividades por preços mais elevados.

Já, com relação às motivações para não aumentar a terceirização de atividades logísticas, os embarcadores do primeiro grupo - maiores níveis de formalização organizacional e baixos níveis de adoção de TIs - consideram que possuem maior capacidade que os prestadores de serviço na execução de tarefas operacionais e na proposição de soluções logísticas, sobretudo nas atividades internas de programação de compras, de produção e de entrega. Os embarcadores desse grupo, apesar do baixo nível de adoção de TIs, consideram, também, que os prestadores de serviço logístico não utilizam TIs adequadas para a programação dessas operações. Diante desse quadro, é forte a percepção de que a utilização de ativos próprios não seria reduzida e que o tempo e esforço gerencial gastos com logística não diminuiriam nessas atividades internas. Em essência, os embarcadores do primeiro grupo consideram que o aumento da terceirização das atividades internas não proporcionaria os níveis de eficiência operacional desejados.

\begin{tabular}{|c|c|c|c|c|c|}
\hline $\begin{array}{c}\text { Atividades } \\
\text { Externas }\end{array}$ & \multicolumn{3}{|c|}{ Atividades Internas } & $\begin{array}{c}\text { Atividades } \\
\text { Externas }\end{array}$ \\
\hline $\begin{array}{c}\text { Suprimento } \\
\text { dos } \\
\text { Fornecedores }\end{array}$ & $\begin{array}{c}\text { Programação } \\
\text { de } \\
\text { Compras }\end{array}$ & $\begin{array}{c}\text { Programação } \\
\text { de } \\
\text { Produção }\end{array}$ & $\begin{array}{c}\text { Programação } \\
\text { de Entrega } \\
\text { (Roteirização) }\end{array}$ & $\begin{array}{c}\text { Separação } \\
\text { E }\end{array}$ & $\begin{array}{c}\text { Distribuição } \\
\text { aos } \\
\text { Eercados }\end{array}$ \\
\hline & & & & \\
\hline
\end{tabular}

Figura 3. Motivações à Terceirização de Atividades Logísticas em Embarcadores do Primeiro Grupo.

\begin{tabular}{|c|c|c|c|c|c|}
\hline $\begin{array}{c}\text { Atividades } \\
\text { Externas }\end{array}$ & \multicolumn{3}{|c|}{ Atividades Internas } & $\begin{array}{c}\text { Atividades } \\
\text { Externas }\end{array}$ \\
\hline $\begin{array}{c}\text { Suprimento } \\
\text { dos } \\
\text { Fornecedores }\end{array}$ & $\begin{array}{c}\text { Programação } \\
\text { de } \\
\text { Compras }\end{array}$ & $\begin{array}{c}\text { Programação } \\
\text { de } \\
\text { Produção }\end{array}$ & $\begin{array}{c}\text { Programação } \\
\text { de Entrega } \\
\text { (Roteirização) }\end{array}$ & $\begin{array}{c}\text { Separação } \\
\text { e } \\
\text { Endereçamento }\end{array}$ & $\begin{array}{c}\text { Distribuição } \\
\text { aos } \\
\text { Mercados }\end{array}$ \\
\hline $\begin{array}{c}\text { Redução de } \\
\text { Custos }\end{array}$ & \multicolumn{3}{c}{ Redução do Investimento em Ativos } & Melhoria Contínua \\
\hline
\end{tabular}

Figura 4. Motivações à Terceirização de Atividades Logísticas em Embarcadores do Segundo Grupo. 
Finalmente, os embarcadores do segundo grupo - menores níveis de formalização organizacional e adoção intensiva de TIs - consideram a divulgação de informações confidenciais da empresa, sobretudo na programação de operações, manuseio de materiais e rastreamento de carregamentos, o principal motivo para não aumentar a terceirização de atividades logísticas. Embarcadores desse grupo também consideram que os preços cobrados pelos prestadores de serviço na execução de atividades internas são elevados e não compensariam uma eventual redução no investimento em ativos, advinda da terceirização de uma maior parte das atividades internas. Há também o receio de que os níveis de serviço logístico poderiam não ser atendidos no manuseio de materiais, em que embarcadores desse grupo buscam maiores níveis de flexibilidade operacional a partir de iniciativas de melhoria contínua. O mesmo receio está presente no rastreamento de carregamentos.

\section{Conclusões}

Esta pesquisa procurou avaliar o impacto das diferentes dimensões de sofisticação da organização logística dos embarcadores brasileiros do setor industrial, nas motivações à terceirização de atividades logísticas. Seus resultados revelaram que as dimensões de sofisticação, extraídas a partir de variáveis ligadas à formalização or- ganizacional, à tecnologia de informação e ao monitoramento de desempenho explicam significativamente as diferenças nas motivações de dois grupos distintos de embarcadores: (1) embarcadores com maiores níveis de formalização organizacional e baixos níveis de adoção de TIs; e (2) embarcadores com menores níveis de formalização organizacional e adoção intensiva de TIs.

Embarcadores do primeiro grupo tendem a apresentar maiores restrições à terceirização de atividades internas como a programação de compras, de produção e de entregas, sendo maiores as oportunidades para a terceirização nas atividades externas, associadas à distribuição aos mercados e ao suprimento dos fornecedores. Já, com relação aos embarcadores do segundo, as oportunidades para a terceirização são igualmente distribuídas por toda sua cadeia de valor, no entanto, há o receio de que os prestadores de serviço não sejam suficientemente flexíveis na distribuição nem eficientes em custos, na produção e no suprimento.

Análises futuras devem ser conduzidas na amostra coletada para complementar o quadro conceitual apresentado. Por exemplo, estas análises teriam como objetivo relacionar os dois grupos de embarcadores a outras variáveis características do negócio, como, por exemplo, setor da economia, custo adicionado dos produtos, estrutura do processo produtivo $(\mathrm{V}, \mathrm{A}, \mathrm{T})$, dentre outras.

\section{Referências Bibliográficas}

BOWERSOX, D. J.; CLOSS, D. J.; STANK, T. P. $21^{\text {st }}$ century logistics: making supply chain integration a reality. Oak Brooks: Council of Logistics Management, 1999. $264 \mathrm{p}$.

BOWERSOX, D. J.; DAUGHERTY, P. J. Logistical excellence: it's not business as usual. Burlington: Digital Press, 1992. 205 p.

CASTRO, C. M. A prática da pesquisa. São Paulo: McGraw-Hill, 1978. 156 p.

FIGUEIREDO, K. F.; FLEURY, P. F.; WANKE, P. Logística e gerenciamento da cadeia de suprimentos: planejamento do fluxo de produtos e dos recursos. São Paulo: Editora Atlas, 2003. 483 p.

FLEURY, P. F.; RIBEIRO, A. A indústria de prestadores de serviços logísticos no Brasil: caracterizando os principais operadores. In: ENCONTRO ANUAL DA ANPAD, 27., Campinas, 2001. Anais...Campinas: ANPAD, 2001. CD-ROM.

HAIR, J. F.; ANDERSON, R. E; TATHAM, R. L. Multivariate data analysis. New York: Prentice Hall, 1998. 810 p.

KLEINBAUM, D.; KUPPER, L.; MULLER, K. Applied regression analysis and other multivariable methods. New York: Duxbury Press, 1998. 797 p.

LAMBERT, D. M.; STOCK, J. R. Fundamentals of logistics management. New York: Irwin-McGraw Hill, 1998. $611 \mathrm{p}$.

LAVALLE, C.; FLEURY, P. F. Avaliação da organização logística em empresas da cadeia de suprimentos de alimentos. Revista de Administração Contemporânea, Curitiba, v. 4, n. 1, p. 47-67, 2000.

MENTZER, J.T.; FLINT, D.J. Validity in logistics research. Journal of Business Logistics. Oak Brooks, v. 18, n. 1, p. 199-216, 1997.

SINK, H. L.; LANGLEY, J. C. Buyer observations of the US third-party logistics market. International Journal of Physical Distribution \& Logistics Management. Northampton, v. 26, n. 3, p. 38-46, 1996.

SINK, H. L.; LANGLEY, J. C. A managerial framework for the acquisition of third-party logistics services. Journal of Business Logistics. Oak Brooks, v. 18, n. 2, p. 163189, 1997.

TABACHNICK, B. G.; FIDELL, L. S. Using multivariate 
statistics. Boston: Allyn and Bacon, 2001. 966 p.

VAN AMSTEL, W. P.; STARREVELD, D. W. Does your company need a logistical executive? The International Journal of Logistics Management. Columbus, v. 4, n. 1, p. 48-58, 1993.
WANKE, P. Parcerias entre fabricantes e prestadores de serviço logístico no Brasil: modelo conceitual e estudos de caso. 1998. 165 f.. Dissertação (Mestrado em Engenharia de Produção) - COPPE, Universidade Federal do Rio de Janeiro, 1998.

\section{IMPACT OF INDUSTRIAL COMPANIES' SOPHISTICATED LOGISTICS ON OUTSOURCING}

\section{Abstract}

An evaluation was made to identify how the different degrees of sophistication in the logistical organization of Brazilian industrial companies affect their decision to outsource logistic services. To this end, based on a review of the literature, variables relating to the sophistication of logistic organization and the main reasons for deciding to outsource were defined. 218 questionnaires were mailed to industrial companies listed in Exame magazine. The 93 companies that filled out the questionnaire were divided into two groups based on their reasons for outsourcing logistic services: (1) companies with high levels of formal organization and low levels of IT use, and (2) companies with low levels of formal organization but high levels of IT use. The findings are discussed from the standpoint of opportunities available to outsourced service providers to enhance the logistical services they offer to these two groups of companies.

Keywords: outsourcing, logistics, motivators, Brazilian companies. 